University for Business and Technology in Kosovo

UBT Knowledge Center

UBT International Conference

2018 UBT International Conference

Oct 27th, 10:45 AM - 12:15 PM

\title{
An implementation of Weighted Least Squares method in Central Bank Twitter Accounts Grew prediction
}

\author{
Goran Bjelobaba \\ National Bank of Serbia, goran.bjelobaba@nbs.rs \\ Ana Savic \\ School of Electrical Engineering and Computer Science, ana.savic@viser.edu.rs \\ Radosav Veselinovic \\ University of Belgrade, veselinovic.ceda@gmail.com \\ Hana Stefanovic \\ ComTrade, hana.stefanovic@its.edu.rs
}

Follow this and additional works at: https://knowledgecenter.ubt-uni.net/conference

Part of the Computer Sciences Commons, and the Digital Communications and Networking Commons

\section{Recommended Citation}

Bjelobaba, Goran; Savic, Ana; Veselinovic, Radosav; and Stefanovic, Hana, "An implementation of Weighted Least Squares method in Central Bank Twitter Accounts Grew prediction" (2018). UBT International Conference. 83.

https://knowledgecenter.ubt-uni.net/conference/2018/all-events/83

This Event is brought to you for free and open access by the Publication and Journals at UBT Knowledge Center. It has been accepted for inclusion in UBT International Conference by an authorized administrator of UBT Knowledge Center. For more information, please contact knowledge.center@ubt-uni.net. 


\title{
An implementation of Weighted Least Squares method in Central Bank Twitter Accounts Grew prediction
}

\author{
Goran Bjelobaba1, Ana Savic2, Radosav Veselinovic ${ }^{3}$, Hana Stefanovic4 \\ ${ }^{1}$ The National Bank of Serbia, Kralja Petra 12, 11000 Belgrade, Republic of \\ Serbia goran.bjelobaba@nbs.rs \\ 2 The School of Electrical Engineering and Computer Science Applied Studies, \\ Vojvode Stepe 283, 11000 Belgrade, Republic of Serbia \\ ana.savic@viser.edu.rs \\ ${ }^{3}$ Faculty of Economics, University of Belgrade, Kamenicka 6, 11000 Belgrade, \\ Republic of Serbia \\ veselinovic.ceda@gmail.com \\ ${ }^{4}$ ComTrade, Information Technology School of Applied Studies, Savski nasip 7, 11000 \\ Belgrade, Republic of Serbia \\ hana.stefanovic@its.edu.rs
}

\begin{abstract}
This paper presents some advantages of using social media and social networks as an efficient way of Central Banks communication with target audience. The statistics given in this paper presents some leading banks based on number of followers on Twitter in 2018, showing that Indonesia's Central Bank has more Twitter followers than any other monetary authority, beating out the Banco de Mexico, Federal Reserve, European Central Bank and Reserve Bank of India. In this paper some prediction of number of Twitter followers in Central Bank communication is also contributed, based on Weighted Least Squares method. An algorithm is implemented in MATLAB, while weights are used to minimize the error between the predicted and actual output sequence, presented with number of followers for each bank.
\end{abstract}

Keywords: Social networks, Central Bank, Weighted Least Squares method, Facebook/Twitter accounts

\section{Introduction}

One of the main challenges for Central Banks is to appropriately, taking into account all the obstacles that communicating with a wider public entails, react in a timely manner and in accordance with the specific target groups, on topics that interest them, the state of the market and the general interest of the public in relation the work of the Central Bank. As the global economic recovery strengthens and Central Banks move 
to raise interest rates, they need to improve their communication using social media to manage expectations [1]. Using official social media channels, Central Banks are communicating with a wider public [2], as well as with the target groups, using the interaction that social networks allow. Since communication is an essential element of any policy of Central Banks, including public expectation management and the impact that its communication has in financial markets, the content that Central Banks publish and the manner in which they do it has never been more important, nor more followed [3].

Another thing we can say with certainty is that a greater pro-activity on social networks will gradually abolish the need for conventional telephone customer service centers [4]. Even today, a significant number of Central Banks following networks activity with great care, such as Twitter or Facebook and consider the opinions of the followers. Objections of users will be available to banks in real time, so the bank will proactively participate in the discussion and influence the preservation of its reputation. In order to effectively use social media, Central Banks need to understand the use of tools to achieve interaction with the target groups, as well as the way in which they can use feedback received from them for the consideration and preparation of an adequate response. Engaging in social media is certainly not an easy task for Central Banks in the world. An even greater challenge is for them to build and maintain a successful presence in the online environment without its own control. Central Bank is, by definition, a very conservative institution which is prone to complete control. Precisely, the lack of control was a major reason of the hostility Central Banks have towards social media. Nowadays, the most of Central Banks provide followers on Twitter and/or Facebook, with a variety of content including links to media releases, speeches, publications, adverts and other publicly available material [5]. A majority of Central Banks use Twitter to send alerts for information already disseminated through the website, even as some of them are not very active in responding to public tweets [6]. YouTube is the third-most popular social media, usually used for consumer awareness and education. One study from 2017 also highlighted that Linkedln, Instagram, Flickr are also catching the fancy of some for connecting with the youth. The European Central Bank (ECB) wants to understand how social media users discuss monetary policy and banking supervision, as well as other topics relevant to the ECB and like other public institutions, so bank management analyses social media activity related to their tasks and monitor the use of European Central Bank own social media channels [7].

In this paper some prediction of number of Twitter followers in Central Bank communication is contributed, based on Weighted Least Squares method [8], in the MATLAB environment, using weights to minimize the error between the predicted and actual output sequence, presented with number of followers for each bank analyzed in this paper.

This paper is organized as follows. Section 2 describes some advantages of using social media and social networks in Central Banks' communication which changed dramatically over the past decades, while Section 3 introduces Weighted Least Squares algorithm, used to analyze and predict number of Twitter followers in Central Banks' communication. Measured and predicted number of Twitter followers using Weighted Least Squares are computed, illustrated and discussed also in Section 3, for different values of relevant parameters. Finally, Section 4 presents our conclusions. 


\section{Central Banks in Social Networks}

Post the global financial crisis, there has been a dramatic change in the use of Central Bank communications as a Central Bank policy instrument. In the last ten years, there is a growing trend of Central Banks' presence in social media. Some banks use their presence on social networks to channel traffic to their main site, while others use their presence to spread useful and informative content to different target groups in accessible way.

Central Banks communicate qualitative information to the financial market through statements, minutes, speeches, and published reports, while the social networks channels are very important communication tool that a Central Bank can use to avert a crisis, by providing investors with its assessment of the risks and the measures it views as necessary to reduce those risks within the economy [9].

Previous studies suggest that effective Central Bank communications can mitigate and potentially prevent a financial crisis, and ineffective communications may exacerbate one [1].

Central Banks' platform in social networks analysis presented in this paper is conducted in order to determine trends in the use of social networks in communication of Central Banks with media and public. The expansion of social media in the last ten years shows that this area offers enormous opportunities and that they will eventually get bigger. The whole world becomes increasingly interdependent due to interactions that social networks provide. They represent a powerful way to connect central banks with the public [10]. A new Central Banking journal study shows that institutions around the world are adopting very different approaches in their deployment of social media techniques.

The number of people following the top 10 monetary authorities on the socialmedia website jumped 51 percent to just over 2 million in 2015, according to a survey by Central Banking Publications. The Federal Reserve proved the most popular, with the number of followers to the account of its Board of Governors climbing 62 percent to 304,000. Mexico's central bank was second with 301,000, followed by the European Central Bank and Bank Indonesia, in 2015 [11].

About 60 Central Banks operate at least one account through either Twitter or Facebook, the two most popular, at least in the English-language speaking world social media networks, more than 20 use both Twitter and Facebook, but more than 30 Central Banks solely use Twitter, while more than 10 use only Facebook [1].

Bank Indonesia has about 625,000 Twitter followers, the most of any Central Bank, as it is presented in Table 1. Among its almost 12,000 tweets are updates on exchange rates and inflation, prize giveaways and even a jaunty music video explaining how to spot fake bank notes.

The interest rate in Central Banks is rising on Twitter, as it is presented in Table 1 , showing the Twitter followers grew in last ten years [10]. Of the Central Banks that operate an account on Twitter and/or Facebook [12], more than half are based in Europe and North America, around a third are from South America and Asia, and the rest are split between Africa and Oceania [6].

Nigeria provides another useful example of the issues that can occur. The Central Bank of Nigeria this year forced the closure of more than 100.000 (100 K) social networking accounts or followers. The Central Bank of El Salvador uses Facebook 
predominantly to target students, and releases "small educational capsules" about a range of economic and financial concepts, while Twitter is used primarily for post information related to economic growth and its also useful tool for two-way communication with the public. The South African Reserve Bank's (Sarb) is one of the most frequent tweeters in Africa, as highlighted in Table 1. However, tweeting in large quantities does not necessarily guarantee a large audience. In terms of followers, the Bank of Mexico leads the way with more than $300 \mathrm{~K}$. The Central Bank of Colombia and the Federal Reserve have similar followings [1].

Table 1. Number of Twitter followers in Central Bank communication in 2012 and 2018.

\begin{tabular}{llll}
\hline Central Bank & Public Twitter Account & $\begin{array}{l}\text { Twitter } \\
\text { followers 2012. }\end{array}$ & $\begin{array}{l}\text { Twitter } \\
\text { followers 2018. }\end{array}$ \\
\hline European Central Bank & @ecb & $<300 \mathrm{~K}$ & $430 \mathrm{~K}$ \\
WSJ Central Banks & @WSJCentralBanks & $<60 \mathrm{~K}$ & $95 \mathrm{~K}$ \\
Federal Reserve & @federalreserve & $<300 \mathrm{~K}$ & $465 \mathrm{~K}$ \\
Central Bank of India & @centralbank_in & $<200 \mathrm{~K}$ & $320 \mathrm{~K}$ \\
Central Bank of Kenya & @CBKKenya & $<80 \mathrm{~K}$ & $130 \mathrm{~K}$ \\
Danmarks National Bank & @nationalbanken & $<2 \mathrm{~K}$ & $5 \mathrm{~K}$ \\
Swiss National Bank & @SNB_BNS_en & $<2 \mathrm{~K}$ & $4 \mathrm{~K}$ \\
Central Bank if Nigeria & @cenbank & $<80 \mathrm{~K}$ & $142 \mathrm{~K}$ \\
Central Bank of Indonesia & @bank_indonesia & $<300 \mathrm{~K}$ & $640 \mathrm{~K}$ \\
Sveriges riskbank & @riskbanken & $<6 \mathrm{~K}$ & $10 \mathrm{~K}$ \\
Deutsche Bundesbank & @bundesbank & $<15 \mathrm{~K}$ & $25 \mathrm{~K}$ \\
Latvijas Banka & @LatvijasBanka & $<5 \mathrm{~K}$ & $8 \mathrm{~K}$ \\
Ufficio Stampa della Banca d'Italia & @UfficioStampaBI & $<10 \mathrm{~K}$ & $18 \mathrm{~K}$ \\
Finland Central Bank & @SuomenPankki & $<5 \mathrm{~K}$ & $8 \mathrm{~K}$ \\
Bank of Japan & @Bank_of_Japan_e & $<15 \mathrm{~K}$ & $22 \mathrm{~K}$ \\
South African Reserve Bank & @SAReserveBank & $<15 \mathrm{~K}$ & $32 \mathrm{~K}$ \\
Banco de Mexico & @Banxico & $<300 \mathrm{~K}$ & $595 \mathrm{~K}$ \\
\hline
\end{tabular}

\section{$3 \quad$ Weighted Least Squares Method in Number of Twitter Followers Prediction}

Least squares method is used to compute the parameter vector $\theta$ which minimizes the square of the error between the predicted value $h_{\theta}(x)$ and the actual output $y$ for all $j$ values in the training set [8]. All the $j$ values in the training set could be given equal importance, but if some observations are known to be more important than the other, we can use weighted least squares method.

The predicted number of Twitter followers in Central Bank communication, according to Table 1 , using a hypothesis $h_{\theta}(x)$ is defined as:

$$
h_{\theta}(x)=\theta_{0} x_{0}+\theta_{1} x_{1}+\ldots=\sum_{i=0}^{n-1} \theta_{i} x_{i}=\theta^{T} x
$$


where $m$ presents the number of training set, in our case top 20 central banks [13], $x$ is the input sequence (the bank index), $y$ is the output sequence (the number of followers for each bank), $n$ is the number of features/parameters, which is set to 2 for this example. The value of $\left(x^{j}, y^{j}\right)$ corresponds to the $j^{\text {th }}$ training set, where $w^{j}$ is the weight given to the $j^{\text {th }}$ training set. The objective of method is to find the parameter vector $\theta$ which minimizes the square of the error between the predicted value $h_{\theta}(x)$ and the actual output $y$ for all $j$ values in the training set with weight $w^{j}[8]$ : $\min \sum w^{j}$

$$
j=0
$$

Using matrix algebra, it is obtained [14]:

$$
\sum w^{j}\left\lceil\left\lfloor h_{\theta} h_{\theta}\left(x^{j}\right)-y^{j}\right\rceil\right\rfloor^{2}=(X \theta-Y)^{T} W(X \theta-Y)
$$

where $W$ is the diagonal matrix of dimension $[m \times m]$ :

$$
W=\left[\begin{array}{cccc}
w^{1} & 0 & \ldots & 0 \\
& & & \\
0 & w & \ldots & 0 \\
\vdots & \vdots & \ddots & \vdots \\
0 & 0 & \ldots & w^{m}
\end{array}\right] .
$$

$X$ is is the input sequence matrix of dimension $[m \times n]$ :

$$
\left.X=\mid \begin{array}{cc}
x^{1} & x^{1} \\
02 & 12 \\
x_{0} & x_{1} \\
\vdots & \vdots \\
x^{m} & x^{m} \\
0 & 1
\end{array}\right],
$$

$Y$ is is the measured values matrix of dimension $[m \times 1]$ :

$$
\begin{gathered}
\begin{array}{c}
y^{1} \\
Y= \\
\mid
\end{array} \mid \\
|\vdots|, \mid
\end{gathered}
$$

while $\theta$ is the parameter vector of dimension $[n \times 1]$ :

$$
\theta=\left\lceil\begin{array}{l}
\theta_{0} \\
\left\lfloor\theta_{1}\right.
\end{array}\right\rfloor
$$


The cost function $J(\theta)$ is defined as:

$J(\theta)=\underset{m}{{ }^{1} \sum_{w j}} \quad\left\lfloor h_{\theta}\left(x^{j}\right)-y^{j} \rrbracket^{2} \quad={ }^{1}(X \theta-Y)^{T} W(X \theta-Y)\right.$.

2

$j=1$

In order to find the value of $\theta$ which minimizes $J(\theta)$, we can differentiate $J(\theta)$ with respect to $\theta$ :

$$
\partial^{\partial} \theta J(\theta)=0 \Leftrightarrow\left(X^{T} W X \theta-X^{T} W Y\right)=0 .
$$

According to (9), the weighted least squares solution is:

$$
\theta=\left(X_{T} W X\right)^{-1} X_{T} W Y
$$

In this paper, an exponentially weighting function is used:

$$
w_{j}=\left.\exp \right|_{\mid} ^{l}-\left.\frac{\left(x_{j}-x\right)^{2}}{2 \tau^{2}}\right|_{j} ^{\prime} \text {. }
$$

An additional parameter $r$ controls the width of the weighting function, where higher value of $r$ gives the wider weight function.

Measured and predicted number of Twitter followers using weighted least squares are computed and illustrated in Fig. 1.

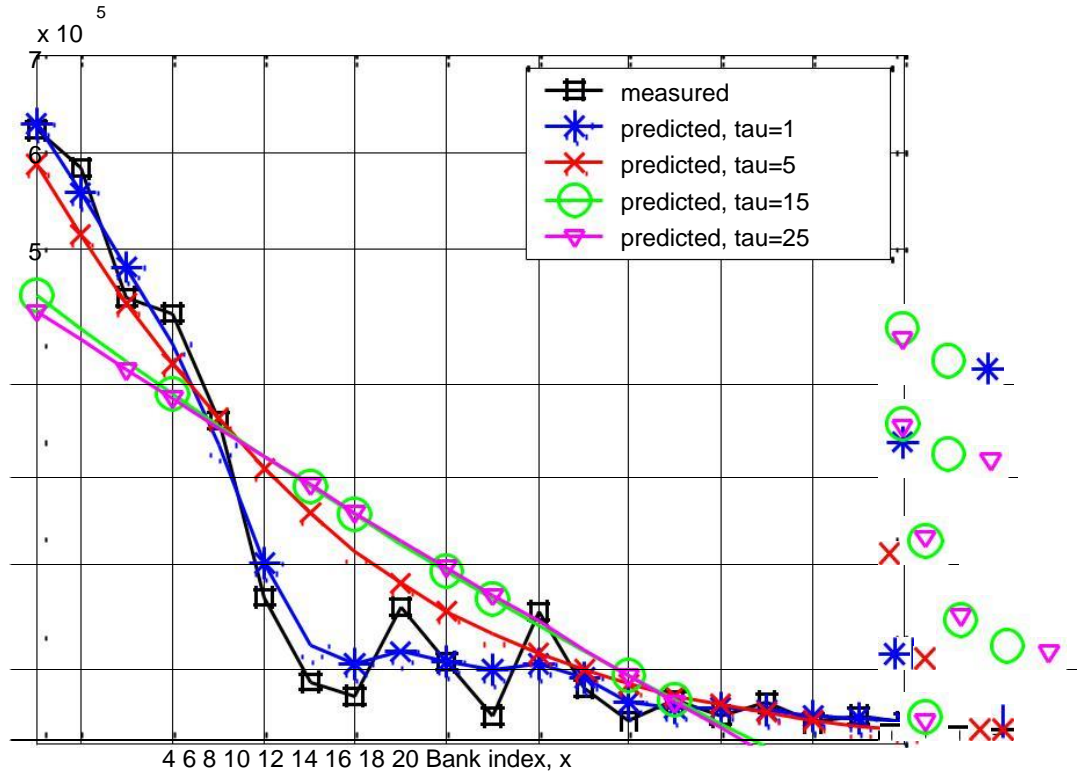

Fig. 1. Predicted number of Twitter followers in Central Bank communication 
It can be concluded that for smaller value of $T(T=1)$ the predicted and measured values are almost on top of each other, while higher value of $T$ ( $T=15$ or more) correspond to the no weighting case. Locally weighted case gives better results, but user needs to have the training set handy to compute the weighted function.

In this paper, number of re-tweets, impressions, engagements or clicks/total clicks, demographics and other metrics that give additional insights into how Central Banks are resonating with their audience, are not analyzed, but it could be a subject to our further research. After signing in with personal account to apps.twitter.com and creating a Twitter application [15] to generate a Consumer Key, Consumer Secret, Access Token and Access Token Secret it is possible to analyze tweets in different ways in order to evaluate Twitter data to inform business decisions [16]. Using Twitter's built-in analytics tool could improve analysis given in this paper.

\section{Conclusion}

Weighted Least Squares is an efficient method that makes good use of small data sets. It also shares the ability to provide different types of easily interpretable statistical intervals for estimation, prediction, calibration and optimization. The implementation of social media and social networks in Central Banks' communication has become a necessity considering the large millennial population, and its growth prediction using Weighted Least Squares method presented in this paper, gives good results. Future research will include some analysis of number of re-tweets, impressions, engagements or clicks/total clicks, demographics and other metrics that give additional insights into how Central Banks are resonating with their audience.

\section{References}

1. https://www.centralbanking.com/central-banks/governance/2266650/central-banksadopting-social-media-at-different-paces-finds-cbj-study

2. Radenkovic, B., Despotovic-Zrakic, M., Bogdanovic, Z., Barac, D., Labus, A.: Elektronsko poslovanje, Beograd: Fakultet organizacionih nauka (2005)

3. https://www.ifac.org/publications-resources/public-sector-specific-financial-instruments

4. Safko, L.: The Social Media Bible: Tactics, Tools, and Strategies for Business Success, NJ: John Wiley \& Sons (2010)

5. https://twitter.com/search?q=\%23centralbank

6. https://www.americanbanker.com/articles/which-central-bank-has-the-most-twitterfollowers-hint-its-not-the-fed

7. https://www.ecb.europa.eu/home/socialmedia/monitoring/html/index.en.html

8. Wolberg, J.R., Wolberg, J.: Data Analysis Using the Method of Least Squares: Extracting the Most Information from Experiments, Berlin Germany: Springer (2006)

9. Qualman, E.: Socialnomics: How social media transforms the way we live and do business (2nd ed.). NJ: John Wiley \& Sons (2012)

10. Westerman, D., Spence, P. R., Van Der Heide, B.: A social network as information: The effect of system generated reports of connectedness on credibility on Twitter. Computers in Human Behavior, (2012) 28(1), 199-206 
11.https://www.statista.com/

12. Ediger, D., Jiang, K., Riedy, J., Bader, D. A., Corley, C.: Massive social network analysis: Mining Twitter for social good. In 39th International Conference on Parallel Processing (ICPP 2010), San Diego, CA, (2010) 583-593

13. Bjelobaba, G., Savic, A., Stefanovic, H.: Analysis of central banks platforms on social networks. In International Conference on Computer Science and Communication Engineering Proceedings (UBT 6th Annual Int. Conf.), Durres, Albania, (2017) 17-21

14. Golub, G.H., Loan, C.F.: Matrix Computations (3rd ed.). Baltimore and London: John Hopkins University Press (1996)

15. https://apps.twitter.com/

16. Popovic, M., Milosavljevic, M.: Twitter data analytics in education using IBM Infosphere Biginsights. In International Scientific Conference on ICT and EBusiness Related Research (SINTEZA 2016), Belgrade, Serbia, (2016) 74-80 